\section{CPS-010 INSULIN PRESCRIPTION ANALYSIS IN A THIRD-LEVEL HOSPITAL}

E Elvira Ladrón de Guevara, Verdejo Reche*, B Tauste Hernández, E Martinez Velasco, F Sierra García, E Tejedor Tejada. C.H.Torrecárdenas, Pharmacy, Almeria, Spain

10.1136/ejhpharm-2019-eahpconf.159

Background Hyperglycaemia is very frequent in hospitalised patients, increasing the risk of complications, disability and death. An adequate control through the use of insulin is especially important in reducing these. The most recommended administration regimen consists of a basal insulin, a prandial insulin and a scheme correction should replace the monotherapy of insulin with a scheme of correction, since this is ineffective and even entails some risks.

Purpose To analyse the suitability of prescribing insulin guidelines in patients admitted to a third-level hospital based on the recommendations of the Local Society of Endocrinology, Diabetes and Nutrition.

Material and methods Descriptive observational cross-sectional study. All non-critical patients diagnosed with diabetes mellitus who started treatment with insulin (slow action) for 15 days were included. Variables collected: age, sex, basal insulin dose, bolus dose, bolus correction dose and whether or not they had an oral diet in order to evaluate the adequacy of treatment. The prescriptions that followed the Local Society recommendations were considered correct: dose of insulin if oral diet: $50 \%$ basal $+50 \%$ prandial bolus $(30 \%$ breakfast, $40 \%$ lunch and 30\% dinner) \pm correction dose; if not oral diet: $50 \%$ basal \pm correction regime.

Results Sixty patients were included (average age: 74.68 years (42-90); 56.66\% males $(n=34)$ and $43.33 \%$ females $(n=26)$. Insulin prescription was: $98.33 \%(\mathrm{n}=59)$ insulin glargine and $1.66 \%(\mathrm{n}=1)$ insulin degludec. Fifty-seven (955) patients had an oral diet. Of these, eight (14.03\%) were considered correct prescriptions. Among the considered incorrect prescriptions (85.96\%), the errors were: $57.14 \%$ did not have a bolus prescription, $30.61 \%$ did not adjust the $50 \%$ basal dose $+50 \%$ bolus dose and $12.24 \%$ had negative correction higher than the prescribed. No dietary data were obtained from three patients and, therefore, the study was not followed in them.

Conclusion According to the results obtained and, although the study has limitations such as the lack of registration of glycemia and the possibility that some patients do not need bolus doses for blood glucose control, it is clear that there is much to improve. This work opens the way to continue deepening the subject and making appropriate interventions.

\section{REFERENCES AND/OR ACKNOWLEDGEMENTS}

Colleges.

No conflict of interest.

\section{CPS-011 PREVALENCE AND RELATIONSHIP BETWEEN HYPOVITAMINOSIS D AND INSULIN RESISTANCE IN OBESE PATIENT CANDIDATES FOR BARIATRIC SURGERY}

\footnotetext{
${ }^{1} \mathrm{D}$ Blánquez Martínez, ${ }^{2} \mathrm{M}$ Hayon Ponce, ${ }^{1} \mathrm{P}$ Nieto Gómez, ${ }^{1}$ ÁS Raquel* , ${ }^{1} \mathrm{X}$ Diaz Villamarin, ${ }^{1} \mathrm{C}$ Garcia Fernandez, ${ }^{1} \mathrm{C}$ Davila Fajardo. ${ }^{1}$ Hospital Universitario San Cecilio, Farmacia Hospitalaria, Granada, Spain; ${ }^{2}$ Hospital Universitario San Cecilio, Endocrinología y Nutrición, Granada, Spain
}

10.1136/ejhpharm-2019-eahpconf.160
Background Low vitamin D levels have been postulated to be associated with insulin resistance, suggesting that vitamin D plays a role in glucose metabolism and homeostasis.

Purpose To determine the prevalence of suboptimal vitamin D status in obese patients who are at risk of developing type 2 diabetes and its correlation with insulin resistance.

Material and methods Prospective observational study. We included obese patients (BMI $>30 \mathrm{Kg} / \mathrm{m}^{2}$ ) assisted in endocrinology and nutrition, from October to December 2017. Demographic, clinical and biochemical data were evaluated. Vitamin D insufficiency was defined by 25OHD3 levels between $10-20 \mathrm{ng} / \mathrm{ml}$ and vitamin D deficiency was defined by levels of $25 \mathrm{OHD} 3<10 \mathrm{ng} / \mathrm{ml}$. Insulin resistance was estimated by fasting glucose and the HOMA-IR index $>2.5$. Statistical analyses were performed using the SPSS v.20 program. Associations between continuous variables were evaluated using a univariate linear regression test.

Results We evaluated 85 patients (27 men and 58 women). Mean age $43.8 \pm 14.5$ years. BMI $43.6 \pm 8.2 \mathrm{Kg} / \mathrm{m}^{2}$, systolic blood pressure (SBP) 133.4+-/18.7 $\mathrm{mmHg}$, diastolic blood pressure (DBP) $84.6 \pm 11.1 \mathrm{mmHg}$, fasting glucose 100.8 $\pm 30.6 \mathrm{mg} / \mathrm{dl}$, glycated haemoglobin (HbA1C) 6.01+-/1.05\%, total cholesterol (TC) $18.4 \pm 33.8 \mathrm{mg} / \mathrm{dl}, \mathrm{HDL}$ cholesterol (HDL-c) $47.8 \pm 10.4 \mathrm{mg} / \mathrm{dl}$, LDL cholesterol (LDL-c) 111.5 $\pm 28.2 \mathrm{mg} / \mathrm{dl}$, triglycerides (TG) $152.8 \pm 84.8 \mathrm{mg} / \mathrm{dl}$ and $25 \mathrm{OHD} 317.5 \pm 6.01 \mathrm{ng} / \mathrm{ml}$. $5.88 \%$ of participants had $25(\mathrm{OH})$ D concentrations $<10 \mathrm{ng} / \mathrm{ml}$. Serum levels of $25(\mathrm{OH}) \mathrm{D}$ showed a significant positive association with HOMA2- $\% \mathrm{~S} \quad(\mathrm{p}=0.01)$ and an inverse association with HOMA2-\%B $(\mathrm{p}=0.07)$ and insulin levels $(\mathrm{p}=0.01)$, independent of other factors usually associated with insulin resistance such as age and BMI.

Conclusion Our results highlight the relationship between circulating $25(\mathrm{OH}) \mathrm{D}$ and glucose homeostasis in obese patient candidates for bariatric surgery. Consistent with our findings, a recent study has shown a significant increase in HOMA-IR, $\mathrm{HbA1c}$ and fasting plasma glucose in healthy individuals with serum concentrations of $25(\mathrm{OH}) \mathrm{D}<20 \mathrm{ng} / \mathrm{mL}$ versus those with $25(\mathrm{OH}) \mathrm{D}$ concentrations $>40 \mathrm{ng} / \mathrm{mL}$. We suggest that the optimisation of serum levels of $25(\mathrm{OH})$ D in obese patient candidates for bariatric surgery could represent a preventive strategy against the development of metabolic syndrome, type 2 diabetes and cardiovascular risk. Future prospective intervention studies with a larger sample size are needed to confirm this hypothesis.

\section{REFERENCE AND/OR ACKNOWLEDGEMENTS}

Esteghamati A, Aryan Z, Esteghamati A, et al. Vitamin D deficiency is associated with insulin resistance in nondiabetics and reduced insulin production in type 2 diabetics. Horm Metab Res 2015;47:273-9.

No conflict of interest.

\section{CPS-012 PREVALENCE OF NUTRITIONAL COMPLICATIONS ACCORDING TO THE REQUESTED HOSPITALISATION SERVICE OF TOTAL PARENTERAL NUTRITION}

A Ferrer Machín*, MA Navarro Dávila, M Vera Cabrera, C Fraile Clemente, E Tévar Alfonso, R Mesa Expósito, J Merino Alonso. Hospital Universitario Nuestra Señora la Candelaria, Pharmacy Service, Santa Cruz de Tenerife, Spain

\subsection{6/ejhpharm-2019-eahpconf. 161}

Background Hospital malnutrition is a serious health problem with a high prevalence among hospitalised patients, which 
leads to the use of parenteral nutrition (NP). It should be noted that this artificial technique involves a large number of complications related to its use (metabolic and mechanical).

Purpose To estimate the prevalence of metabolic and mechanical complications depending on the hospitalisation services requesting total parenteral nutrition (NPT).

Material and methods Descriptive study of the nutritional complications of patients undergoing treatment with NPT in 2015.

Patients older than 18 years who were in full follow-up by the endocrinology or pharmacy service of the hospital were selected.

Mechanical complication is defined as that derived from catheter placement (phlebitis, septic,phlebitis, incorrect catheter placement, involuntary catheter leakage, extravasation, pneumothorax, haemothorax, haemomediastinum and venous thrombosis), and as a metabolic complication that is attributable to an excess or deficit of nutrients (sodium, potassium, calcium, phosphorus, magnesium, glucose, triglycerides and cholestasis).

The main variable of the study was the percentage of metabolic and mechanical complications according to the requesting service.

A descriptive analysis was performed through the percentage (\%) for the qualitative ones. In addition, the Chi-square test was used to observe if there were differences between the groups. The analyses were performed using the statistical program SPSS/PC (version 24.0 for Windows, SPSS,Inc., Chicago, IL).

Results NPT was prescribed for 346 patients, of which 140 had some type of nutritional complication. There was at least one type of metabolic complication in 131 patients and at least one type of mechanical complication in 41 patients. Surgical services $(n=79)$ presented $97 \%$ of metabolic complications and $21 \%$ of mechanical complications; medical services $(n=38), 87 \%$ of metabolic complications and $42 \%$ of mechanical complications; the oncological services $(n=18), 100 \%$ of metabolic complications and $17 \%$ of mechanical complications; and medical-surgical services $(n=5), 60 \%$ of metabolic complications and $100 \%$ of mechanical complications.

Conclusion The hospitalisation service that presented the highest percentage of metabolic complications was oncology.

However, the unit that presented the highest percentage of mechanical complications was the medical-surgical unit.

The differences observed in the services were statistically significant, which means that it would be advisable to perform analytical controls and a closer monitoring of the patients of the medical-surgical and oncological services under treatment with TPN.

\section{REFERENCES AND/OR ACKNOWLEDGEMENTS}

No conflict of interest.

\section{CPS-013 ORAL ANTICOAGULANT PRESCRIPTION PRACTICE AFTER AN ISCHAEMIC STROKE}

J Leraut*, S Drouot, S Raspaud, O Chassin, C Denier. CHU De Bicêtre, Val-de-Marne, Kremlin Bicêtre, France

10.1136/ejhpharm-2019-eahpconf.162

Background The National Authority for Health (HAS) updated in 2018 its recommendations on the anticoagulation for vascular prevention after ischaemic stroke.
Purpose The objective was to assess and compare oral anticoagulant $(\mathrm{OAC})$ prescriptions to the guidelines in patients hospitalised for ischaemic stroke in a stroke unit.

Material and methods This was an observational retrospective study of OACs prescriptions including Vitamin $\mathrm{K}$ antagonist (VKA) and direct-acting oral anticoagulant (DOAC) in patients admitted for ischaemic stroke in a comprehensive stroke centre.

Data on prescribed OAC from January to August 2018 was collected from the electronic inpatient records.

The prescriptions' evaluation was based on indication, dosage and drug interactions for DOAC, and indication and bridging anticoagulation for VKA. The thrombotic risk was quantified using the CHA2DS2-VASC score.

Results The mean age of the 86 included patients was 72.8 \pm 14.5 years old (49\% female). About $69 \%$ had an OAC initiation during hospitalisation and $31 \%$ was previously treated.

At hospitalisation discharge DOAC were three times more prescribed than VKA (77\% versus 23\%). DOAC prescriptions of $92 \%$ conformed to the guidelines (dosage and no drug interaction). VKA prescriptions could not be evaluated because of ambulatory follow-up.

The main OAC therapeutic indication was a confirmed atrial fibrillation (AF) in $62 \%$ patients (mean CHA2DS2$\mathrm{VASC}=4.93 \pm 1.36$ ). In $21 \%$, AF was suspected, based on an association of factors such as: atrial hyperexcitability (59\%), dilated left atrium (47\%) and ischaemic stroke background in patients undergoing antiplatelet therapy (23\%) (mean theoretical CHA2DS2-VASC $=4.82 \pm 1.67)$. The remaining indications for OAC were: patent foramen ovale (PFO) before closure (7\%, only DOAC), mechanical heart valve $(5 \%$, only VKA) and antiphospholipid syndrome (APS) (2\%, only VKA).

Conclusion Even though HAS gave no recommendation concerning OAC prescription in patients with an AF suspicion, neurologists prescribe it to prevent relapse stroke risk due to paroxysmal AF. A Holter monitoring is prescribed after discharge to decide upon the continuation of OAC at the neurologist's follow-up visit. This practice should be investigated further to prove its efficiency.

Concerning mechanical heart valves, neurologists follow the HAS recommendations. For PFO, neurologists use DOAC regardless of the HAS recommendations. No recommendation has been given for APS.

\section{REFERENCES AND/OR ACKNOWLEDGEMENTS}

https://www.has-sante.fr/portail/jcms/c_1252051/fr/preventionvasculaire-apres-un-infarctus-cerebral-ou-un-accident-ischemiquetransitoire

No conflict of interest.

\section{CPS-014 ABSTRACT WITHDRAWN}

